\title{
Eguiara y Eguren, Vicente López y san José: devoción personal y devoción oficial al santo en el siglo XVIII novohispano
}

\author{
Eguiara y Eguren, Vicente López and Saint Joseph: \\ Personal and official devotion to the saint \\ in $18^{\text {th }}$ century New Spain
}

\author{
Ana Castaño Navarro \\ Universidad Nacional Autónoma de México, \\ Instituto de Investigaciones Filológicas \\ hijolesana@hotmail.com
}

\begin{abstract}
RESUMEN: Juan José de Eguiara y Eguren (1696-1763) parece haber tenido una clara devoción por san José. Para mostrarlo, en este trabajo nos asomaremos a su tratado teológico, escrito para sus alumnos de la Universidad de México, cuyo título traducido al español reza: Tratado sobre el Santísimo José, Esposo de la Madre de Dios, que incluye dos interesantes paratextos del jesuita Vicente López, y que fue publicado en el tomo 1 de las Selectae Dissertationes Mexicanae... de Eguiara. Se señalan las deudas de éste con la tradición josefina europea y española que le antecede, y se resaltan las que parecen ser sus contribuciones personales a la teología de san José. Igualmente se hace una revisión bibliográfica, tanto de la producción sermonística del bibliógrafo y teólogo novohispano dedicada al santo como de los textos relacionados con san José que se imprimieron, en vida de Eguiara, en su imprenta (Imprenta de la Bibliotheca Mexicana). Por último se señala, entre los trabajos del teólogo novohispano dedicados a san José, una antología manuscrita de sermones sobre el santo escritos por varios autores europeos que parece coincidir con un trabajo similar atribuido a Vicente López que se supone perdido.
\end{abstract}

Palabras CLAVE:

Juan José de Eguiara y Eguren; devoción a san José; sermones y tratados; teología novohispana; Vicente López.

ABSTRACT: Juan José de Eguiara y Eguren (1696-1763) seems to have been clearly devoted to St. Joseph. In order to show this, the following pages will take 
KEYWORDS: Juan José de Eguiara y Eguren; Cult of Saint Joseph; Sermons and treatises; New Spain theology; Vicente López. a look at his Tratado sobre el Santísimo José, Esposo de la Madre de Dios (which includes two interesting paratexts by his friend, the Jesuit Vicente López), published in volume 1 of Selectae Dissertationes Mexicanae..., a complete treatise on Theology written for his students at the Mexican University. Eguiara's debts to previous European and Spanish scholarly tradition on Saint Joseph will be pointed out, as well as his personal contributions to this tradition. Finally, a bibliographical review of this New Spain bibliographer and theologian's homiletic production on Saint Joseph will be made, as well as of the books on Saint Joseph that were printed at his own printing house (Imprenta de la Bibliotheca Mexicana) during Eguiara's lifetime. Finally, among Eguiara's works dedicated to Saint Joseph, a manuscript anthology of sermons on the saint written by different European authors is pointed out, and the possibility is suggested that this work may be the one of similar characteristics that has been attributed to Vicente López and which is now considered lost.

Para acercarnos a las devociones personales de una figura de las letras y de la intelectualidad novohispana como fue el teólogo, bibliógrafo y hombre de letras Juan José de Eguiara y Eguren será necesario, en primer lugar, un análisis cuidadoso de sus obras que tome en cuenta, entre otras cosas, el contexto cultural y religioso en que fueron escritas (cuando se trata de obras literarias) o realizadas (en el caso de gestiones de índole cultural, social, religiosa o política). Aun así, no es fácil calibrar en su justa dimensión la importancia y la magnitud de una devoción, sentimiento que, en buena medida, pertenece al ámbito de la intimidad, como tampoco es sencillo deslindar, en una particular devoción, lo "genuino" o "personal" de lo ideológico, cultural y social.

Hablar de una devoción personal a san José en el siglo XVIII novohispano exige tomar en cuenta que ya para entonces había una bien establecida tradición de culto eclesiástico y popular a este santo, tradición que tuvo como punto de partida las devociones individuales de algunos personajes clave de la Iglesia en Europa a partir del siglo xv, tales como Pierre D'Ailly (1350- ¿1420?), Jean Gerson (1363-1429), Bernardino de 
Siena (1380-1444), Isidoro de Isolano (hacia 1480-1528) o santa Teresa de Jesús (1515-1582). Por otra parte, desempeñaron un papel importante en la difusión de esta tradición ciertas órdenes religiosas, como los franciscanos, los carmelitas, los dominicos y más tarde —y notablemente- los jesuitas, que fomentaron la devoción a san José de diversas formas: en sus pláticas y sermones diarios, mediante la fundación de escuelas, conventos o templos bajo la advocación del santo, a través de diversos escritos como tratados teológicos, obras devocionales, hagiográficas, poético-musicales, etcétera.

Fomentado por el papado, el culto eclesiástico al padre putativo de Cristo paulatinamente siguió cobrando fuerza; además se vio favorecido por el énfasis que, a raíz del Concilio de Trento, puso la Iglesia Católica en el culto a los santos. ${ }^{1}$ Otro factor que fue seguramente decisivo para el florecimiento de la devoción josefina en el mundo católico durante los siglos XVII y XVIII fue el impulso que se dio a la familia como núcleo del sistema social, a cargo de un varón sacrificado, proveedor y protector que, además, era un artífice productivo - carpintero, según la tradición. Así, a la trinidad celeste, formada por el Padre, el Hijo y el Espíritu Santo se contrapuso la trinidad terrestre: Jesús, María y José, modelo de la nueva familia burguesa — de la autoridad paterna y la obediencia por parte del hijo y la esposa-, que constituía la unidad productiva, el núcleo social y moral de la nueva organización ideológica, económica y política europea (Filas 1945: 155-161 y 176-185).

De esa manera, la devoción popular a san José alcanzó un desarrollo importante en la Europa católica y se extendió con fuerza por las colonias

1 En la sesión XXV del Concilio de Trento, celebrada en 1563, en el apartado De la invocación, veneración y reliquias de los Santos y de las sagradas imágenes se resolvió lo siguiente: "Manda el santo Concilio a todos los obispos y demás personas que tienen el cargo y obligación de enseñar, que instruyan con exactitud a los fieles ante todas cosas sobre la intercesión e invocación de los santos, honor de las reliquias y uso legítimo de las imágenes, según la costumbre de la Iglesia católica y apostólica, recibida desde los tiempos primitivos de la religión cristiana y según el consentimiento de los santos Padres y los decretos de los sagrados concilios; enseñándoles que los santos que reinan juntamente con Cristo ruegan a Dios por los hombres; que es bueno y útil invocarles humildemente y recurrir a sus oraciones, intercesión y auxilio para alcanzar de Dios los beneficios por Jesucristo su hijo, nuestro señor, que es solo nuestro redentor y salvador" (1847: 328-329). 
americanas. La Nueva España, por su parte, profesó un culto "oficial" al santo prácticamente desde los inicios de la actividad evangelizadora de los primeros franciscanos, cuando fray Pedro de Gante puso a su colegio el nombre de "San José de los naturales" y, pocos años después, el Primer Concilio Mexicano de 1555 nombró al santo "Patrón general de la nueva Iglesia". ${ }^{2}$

Pues bien, aun tomando en cuenta que para el siglo XVIII esta devoción estaba en buena medida institucionalizada de este lado del Atlántico, existen suficientes datos que pueden hacernos pensar en una inclinación personal de Juan José de Eguiara y Eguren hacia el padre putativo de Jesucristo. En primer lugar, decíamos, hay que buscar estos datos en sus obras escritas. Entre ellas habría que poner especial atención a sus sermones,

2 El Capítulo 18 de ese Primer Concilio Provincial Mexicano dice: "Considerando la grande devoción que el pueblo le tiene y la grande devoción con que de los indios y españoles ha sido y es venerado, recibimos al dicho glorioso san Joseph por patrón general de esta nueva Iglesia". Y treinta años más tarde, en el Tercer Concilio Provincial celebrado en 1585 se insistía: "siendo en verdad extraordinaria la devoción con que se honra, obsequia y reverencia en esta provincia al castísimo esposo de María Santísima..." (Morán 1981: 959). El patronazgo único de san José continuó en México hasta 1746, cuando la Virgen de Guadalupe fue elevada al rango de co-patrona, hecho que marcó el declive de san José en estas tierras, lo que no significó que desapareciera la devoción popular hacia el santo, ni tampoco la de ciertas personalidades individuales o de ciertas órdenes religiosas (Villaseñor 2006: 157, 222). En la nota 2, la autora da la referencia de Cayetano de Cabrera y Quintero, amigo y admirador de Eguiara: Escudo de Armas de México, Celestial Protección de esta Nobilísima Ciudad de la Nueva España y de casi todo el Nuevo Mundo, María Santíssima, en su Portentosa Imagen del Mexicano Guadalupe... México, 1746. Prueba de la vigencia de la devoción a san José, al menos entre la élite eclesiástica — trece años después de la muerte de Eguiara-, es lo que sucedió, en 1776, en la capital novohispana a raíz de una serie de temblores de tierra: "la ciudad organizó una serie de rezos dirigida a su abogado designado para esta causa, san José. De inmediato, el descontento proliferó, y la gente se sorprendió de que las autoridades no se hubieran dirigido a la virgen de Guadalupe. Finalmente la ciudad tuvo que ceder ante la presión popular y aceptó mandar decir una misa a la virgen del Tepeyac en su santuario" (Archivo Histórico del Cabildo Municipal de México, vol. 3604, exp. 9, ápud Ragon 2002: 381-382). La situación en la Península fue algo distinta: en 1621 (un siglo después de consumada la Conquista de México), santa Teresa de Ávila elige al santo como su patrono, y más de medio siglo después, en 1689, Carlos II solicita a Inocencio XI que lo declare "Patrón general de España y todos sus dominios". Sin embargo, pocos años más tarde ese título tuvo que anularse por temor a los conflictos que podían surgir, debido a que Santiago ya era, de hecho, patrón de España. 
pues, para un lector atento, las devociones y preferencias personales de un teólogo pueden transparentarse mejor en estas piezas que en sus tratados estrictamente teológicos, cuyos contenidos eran complejos y delicados desde el punto de vista doctrinal. Además, estos tratados - que por regla general estaban escritos en latín - debían estar escrupulosamente estructurados y controlados; dirigidos a un público especializado, versado en la materia, tenían que apegarse a pautas bien definidas y a una tradición dogmática incontestable. En cambio, por lo general los sermones de los siglos XVII y XVIII, a pesar de pertenecer a un género que llegó a estar también rigurosamente codificado en cuanto a estructura y temas, daban cabida a una cierta espontaneidad, así como a una relativa libertad creativa, y sobre todo elocutiva, por lo cual en ellos tiene cabida la expresión de las emociones y los sentimientos del predicador - aunque la versión pronunciada frente al público sea, en el caso de los sermones de siglos pasados, del todo irrecuperable.

A estos dos tipos de escritos eguiarenses - por un lado, los sermones sobre san José y, por otro, el tratado teológico dedicado al "esposo de la madre de Dios" - me referiré a continuación, así como a algunas pruebas externas que corroboran la devoción que nuestro sabio novohispano sintió por el padre putativo de Jesucristo.

\section{Los sermones}

Para orientarnos en la enorme producción sermonística —manuscrita e impresa- de Eguiara es indispensable la consulta de las bibliografías preparadas por don Ernesto de la Torre Villar (1989b: 207-239) y las dos tesis - de licenciatura y de maestría en la UNAM- de Luz Elena Vergara. En ellas pueden encontrarse varias piezas manuscritas del sabio novohispano dedicadas a san José: al menos 4 sermones, 4 pláticas y 2 apuntes para sermones. ${ }^{3}$ Acerca del primero de los sermones, que lleva por título:

3 Debe considerarse que la división entre sermones, apuntes y pláticas no siempre es clara. Quizá por esa razón encontramos textos titulados "Apuntes de sermón" en el apartado de "Sermones", y viceversa. Sin embargo, por el momento y para el tema que nos ocupa, las cantidades de unos y otros permanecen inalteradas. 
- La congregación de todos los ángeles y hombres santos excedida por san Joseph, observa De la Torre Villar que "se inspira en la alocución pronunciada por el cancelario de París, Juan Gerson, en el Concilio de Constanza" (1989b: 212, núm. 4). ${ }^{4}$ De hecho, no tendría nada de raro que el famoso sermón del eminente teólogo y canciller de la Universidad de París, Jean Gerson, o alguna otra de sus obras dedicadas a fomentar la devoción por san José, hayan influido en Eguiara, como influyeron en tantos hombres de iglesia a lo largo de más de tres siglos. Sin embargo, a pesar de que ambos sermones son elocuentes panegíricos del padre nutricio de Jesucristo, son piezas totalmente diferentes entre sí, tanto en el tono como en la intención y el contenido. Es verdad que Eguiara transcribe una cita del sermón del teólogo parisino; lo hace en un pedazo de papel suelto, con un reclamo que indica el lugar exacto en que debe insertarse, justo antes de comenzar el sexto y penúltimo apartado de su sermón, cuando (según la evidencia material con que contamos) éste ya estaba escrito y copiado en limpio. ${ }^{5}$ Quizá fue esta cita, que alude a las perfecciones angelicales de que gozaron tanto María como José, lo que llevó a De la Torre a pensar que este sermón del erudito novohispano se inspiró en el del canciller de París. ${ }^{6}$ En seguida, el estudioso se hace una pregunta que da

4 El sermón de Eguiara se encuentra en el Ms. 760 de la BNM. Como De la Torre observa, se trata del tercer volumen de manuscritos de Eguiara, y su clasificación antigua es: 83CD/252/años 1727-50. La alocución de Gerson a que se refiere el estudioso es el sermón: "In Festo Nativitatis B. Mariae Virginis. Mt. 1:16" (Gerson 1961: 344-362). Toda esta pieza, dedicada en principio a la Virgen en la fiesta de su nacimiento, es en realidad, como ya apuntamos, un encarecimiento de la figura de san José que se apoya en el hecho de que la Virgen fue su esposa y Jesucristo su hijo. Recientemente ha sido editado un fragmento del sermón de Eguiara con paleografía y notas (Castaño 2019: 95-117).

${ }^{5}$ La cita, que proviene de la primera página del sermón de Gerson, fue copiada dos veces, en dos versiones distintas (una más completa que otra) y por dos manos diferentes: una del mismo Eguiara - la más completa - y otra de un tercer amanuense, en sendos pedazos sueltos de papel que fueron encuadernados con la copia apógrafa del sermón de Eguiara.

6 Eguiara introduce así las palabras del teólogo parisino: "Cierro este discurso, como con llave de oro, con la sentencia del gran doctor y celebérrimo cancelario de París que, predicando a un auditorio tan venerable y por todas partes gravísimo como era 
por sentada la admiración de Eguiara por el santo: “¿De ahí [del sermón de Gersón] derivaría su admiración por san José?" (1989b: 212, núm. 4). En esta admiración por el esposo de la Virgen María nadie había reparado, creo yo, hasta que el padre Roberto Balmori Cinta (jesuita) escribe un detallado análisis y descripción del tratado eguiarense sobre nuestro santo, al que más adelante me referiré (1993: 29-52). ${ }^{7}$

El segundo sermón de Eguiara sobre san José que encuentro en la bibliografía preparada por De la Torre Villar es:

- El ángel de la guarda de Christo, Señor Nuestro, el esclarecido patriarca el Sr. San Joseph. Apuntes del sermón que el día 19 de marzo de 1722, en la Iglesia de la Congregación de el Oratorio de N.P.

el Concilio general de Constancia [sic], a que asistieron casi mil padres congregados de toda la Iglesia, y entre ellos trecientos [sic] obispos, sentó como fundamento de lo mucho que había de decir de nuestro esclarecidísimo patriarca, una elevación eminentísima que, si no me engaño, patrocina cuanto llevo discurrido: Erunt igitur in ambobus perfectiones ceterarum creaturarum ; etiam angelicarum eminenti quodam modo reperibiles. Ex hoc quam late pateat ad commendationem utriusque perspicuum est solerter intuenti campos amplissimos omnium virtutum, donorum, beatitudinum, fructuum spiritus et similium". Si bien en esta cita Gerson compara en cierto modo las perfecciones de los ángeles con las de María y José, y por su parte Eguiara también encarece en su sermón las virtudes del santo comparándolas con las de los ángeles —de hecho colocándolas por encima de las de todos los ángeles congregados-, ambos sermones se estructuran en una forma y con un estilo muy diferentes, y utilizan divisiones, argumentos, pruebas, conceptos y autoridades bíblicas y patrísticas también diferentes. Por esa razón, así como por las palabras con que Eguiara introduce su cita del famoso sermón predicado en el Concilio de Constanza, me atrevo a decir que esa adición tardía responde más bien a que el novohispano quería subrayar las circunstancias solemnes en que el canciller parisino había predicado ese sermón: el muy estratégico Concilio de Constanza, que reunió a una multitud de influyentes prelados y hombres de Iglesia, y donde se tomaron decisiones que determinaron el rumbo del papado y de la Iglesia en Occidente. Todo ello con el fin de establecer un paralelismo entre esas circunstancias y la "congregación de congregaciones" novohispanas (es decir, la reunión de la congregación de san José y la de san Miguel) frente a las que él predicaría - o había predicado, no lo sabemos- su sermón.

7 En otro artículo escrito por esas mismas fechas, De la Torre Villar describe las Selectae Dissertationis Mexicanae... de Eguiara, y observa que al final del primer volumen (el único que se imprimió), después del índice analítico y en la parte baja, hay "una viñeta con el anagrama de Joseph, tan querido de Eguiara" (1992: 332). El énfasis es mío. 
San Phelipe Neri de México, predicó el Dr. Don. Juan Joseph de Eguiara y Eguren (Ms. 762, BNM, ff. $\left.86 r^{\circ}-86 v^{\circ}, 91 r^{\circ}-92 r^{\circ}\right){ }^{8}$ El tercero es:

- El gigante de perfección entre todos los gigantes de santidad. El gran patriarca San Joseph. En Catedral en su día 19 de marzo de 1759 (Ms. 87 CD/252/años 1756-59, vol. 6, núm. 10). El cuarto:

- El Patrocinio incomparable del incomparable Patriarca señor san Joseph. En Catedral en su día a 4 de mayo de 1757. Hecho la víspera (Ms. 87 CD/252/años 1756-59, vol. 6, núm. 12).

Entre los "Apuntes para sermones" registrados por De la Torre Villar en esta misma bibliografía (1989b: 207-239) encuentro los siguientes dedicados a san José:

- Apuntes. Señor San Joseph, patrón contra los temblores (Ms. 90 CD/252/l, vol. 9, núm. 8).

- San José de gracia o la gracia de san José Ventajosa. Sermón en su convento de México en su día de 1754. Entre la esquela de doña Josefa María de Aramburu y Aranguti, 13 de marzo 1754 (Ms. 86 CD/252/años 1752-57, vol. 12, núm. 8).

A continuación, en la "Sección II" del Apéndice IV de esta bibliografía, De la Torre Villar aclara: "Aparte de los volúmenes y sermones ya reseñados. El Dr. Eguiara dejó varios volúmenes de pláticas dadas en diversos sitios. Están manuscritas y en su mayor parte escritas por el propio Eguiara" (1989b: 227-234). Entre ellas encuentro dos sobre san José:

8 La clasificación que da De la Torre Villar es: Volumen quinto (85 CD/252/años 1718-25), núm. 12. También señala: "Estos apuntes sirvieron para sermones de la misma festividad el 23 de marzo de 1738, y el 15 de marzo de 1739" (1989b: 216, núm. 12). Y en efecto, según el índice, en ese volumen hay otras dos pláticas sobre san José (núms. 12 y 13 del manuscrito): "Plática del Sr. San José", y "Otra plática del mismo santo". Al final de dicho índice escribe: "Éstos no permito a imprenta". Agradezco la noticia de estos "apuntes de sermón", así como una copia fotográfica de ellos y de la plática contenida en el Ms. 748, a la doctora Laurette Godinas, del Instituto de Investigaciones Bibliográficas de la UNAM. 
- Plática en el Oratorio 1733-34, 22 de marzo de 1753. Domínica de pasión con fiesta del Sr. San José (1989b: 230, núm. 5) (Ms. 252.4 EGU, 66 CD/252, vol. 3).

- Plática en Oratorio 1733-1734, 28 de marzo de 1734, fiesta de san José y 29 de marzo de 1745 (1989b: 230, núm. 24) (Ms. 252.4 EGU. Adq. 8281, 66 CD/252, vol. 3, en el forro de pergamino: 66 CD/252. Lomo: 750). A éstas habría que añadir las dos pláticas referidas supra: ${ }^{9}$

- "Plática del Sr. San José", y

- "Otra plática del mismo santo".

- Tengo conocimiento de otra —la quinta - plática: "El día de la invención de la Santa Cruz en su víspera. Platica que a 3 de mayo de 1727, víspera del Patrocinio del esclarecido patriarca S. S. Joseph, que en la Iglesia de N. S. S. Phelipe Neri de México predicó el Doctor Don Juan Joseph de Eguiara y Eguren" (Ms. 748, BNM).

Todos estos sermones y pláticas - y seguramente algunos más sobre nuestro santo que aguardan, entre las hojas de tantos volúmenes manuscritos, la oportunidad de ser transcritos y publicados - son sin duda significativos, aunque no basten todavía para probar la devoción de Eguiara por san José, pues hablar de devoción a un santo por parte de un hombre de letras y de iglesia del siglo xvIII mexicano, como hemos visto, exige algo más de detenimiento. Hay que tomar en cuenta, por ejemplo, que en el período novohispano el calendario litúrgico regía la mayoría de las actividades religiosas, culturales y sociales, y que incluía preceptos eclesiásticos para celebrar con misa y sermón - y a veces con música y villancicoslos oficios dedicados a los santos. También hay que considerar el funcionamiento de las diversas cofradías y conventos establecidos en la Nueva España, que promovían activamente el culto a los respectivos santos que habían sido elegidos como patrones. En esas circunstancias, el número de sermones que un prelado mexicano de ese siglo le dedica a un santo en particular no necesariamente es prueba de su devoción personal hacia él. ${ }^{10}$

\footnotetext{
9 Ver nota núm. 8.

10 Según el cálculo de Luz Elena Vergara Castro, Eguiara escribió más de 217 sermones (2016: 36).
} 
También resulta significativo el hecho de que Eguiara compusiera un tratado sobre el esposo de la Virgen, aun tomando en cuenta la proliferación, a partir de finales del siglo XVI, de escritos teológicos dedicados a él, corriente que continuó durante todo el siglo XVII y parte del XVIII en el mundo católico europeo, en la cual tuvieron parte destacada los jesuitas, como hemos dicho. Entre ellos se educó nuestro catedrático, y entre ellos encontró lo mismo grandes amistades —como Vicente López (16911757)—, que grandes figuras directrices — como Francisco Suárez (15481617) y Francisco Toledo (1532-1596).

A los trabajos anteriores del sabio novohispano dedicados a san José hay que añadir una miscelánea manuscrita de textos (la mayoría sermones) de diferentes autores sobre el esposo de la Virgen: De sancto Josepho. ${ }^{11}$ Esta recopilación parece coincidir con un trabajo similar atribuido a Vicente López que se supone perdido (Valdés 2005: 480; véase infra, notas 26 y 27). Bien podría ser que se tratara de una misma obra elaborada por ambos autores a lo largo de varios años, y que fue Eguiara quien se encargó de hacerla pasar en limpio, así como de ponerle un título y un índice con miras a imprimirla.

Ya se ha mencionado la probable influencia en Eguiara del canciller de París, Jean Gerson, gran promotor del culto a san José en Francia y en toda Europa a partir sobre todo del Concilio de Constanza (1414-1418), donde predicó su famoso sermón, al que hicimos referencia líneas arriba, dedicado a la Natividad de la Virgen, y que más que nada es una reflexión,

11 Es el Ms. 556 de la Biblioteca Nacional de México. En el lomo lleva como título: De sancto Josepho. En él están encuadernados, junto con una sección del tratado de Eguiara sobre san José a la que nos hemos referido y fragmentos de otros tratados en latín que aún no he identificado, fragmentos de: un sermón de san Bernardino de Siena; un panegírico a san José escrito por el famoso predicador portugués Antonio Vieira; otro de san Francisco de Sales; extractos de la vida de san José por diferentes autores; un fragmento de un tratado de Pedro Canisio; un breve escrito sin autor, titulado: "De la devoción de San Joseph, esposo de Nuestra Señora" (el único texto en español de todo el manuscrito); un fragmento del tratado sobre san José de Juan de Ávila; otro de un sermón de san Pedro Crisólogo; un fragmento de una epístola de Casiodoro; fragmentos de dos sermones de san Pedro Crisólogo sobre los Evangelios de Marcos y Mateo; un sermón de san Agustín sobre la generación de Cristo, y otro de Eckhardt sobre san José; finalmente, fragmentos de dos sermones del jesuita Juan de Osorio, también sobre el santo. 
al mismo tiempo de tono teológico y afectivo, sobre su esposo. De este autor, asimismo, hay que señalar la Josephina (concluido entre 1417 y 1418), poema heroico latino de tema religioso que narra en cerca de tres mil hexámetros la vida de san José, y que fue el fermento para que, entre otras cosas, se escribieran en España sendas obras dedicadas al padre adoptivo de Jesucristo: el extenso poema narrativo en octavas sobre la vida del santo: Vida, excelencias y muerte del Gloriosísimo Patriarca y esposo de Nuestra Señora San Joseph (Toledo, 1604), de Juan de Valdivielso (¿1560?-1638) y el tratado en prosa del carmelita español, fray Jerónimo Gracián de la Madre de Dios (1545-1614), director espiritual y compañero de santa Teresa de Jesús: Sumario de las excelencias del glorioso san José, esposo de la Virgen María (Toledo, 1605).

De manera que el tratado de Eguiara sobre san José podría leerse, además de como un acto de devoción, como un intento más, por parte del ilustre catedrático mexicano, de filiación cultural y de inserción plena en las corrientes teológicas europeas del siglo precedente. Pero, ¿es ese el caso? Para intentar dar una respuesta a esta pregunta habría que analizar a fondo todo lo que Eguiara escribió sobre nuestro santo, es decir, su Tratado sobre el Santísimo José, Esposo de la Madre de Dios y los sermones sobre el mismo tema que han Ilegado hasta nosotros. Todos estos están, hasta donde tenemos noticia, manuscritos, pues son muy pocos los sermones de Eguiara que llegaron a imprimirse, ${ }^{12}$ y ninguno — hasta donde se tiene no-

12 Casi todos recogidos en un volumen misceláneo de la Sala Mexicana del Fondo Reservado de la Biblioteca Nacional de México (con la Vida del venerable padre Don Pedro de Arellano y Sossa: sacerdote, y primer prepósito de la Congregación del Oratorio de México. México, Imprenta del Empedradillo, 1735 [RSM 1735 M4 EGU]). Entre estos sermones de Eguiara que alcanzaron el honor de la imprenta hay uno dedicado a san Juan de la Cruz, otro a san Esteban protomártir, otro a san Felipe Neri, otro a san Bernardo, otro a san Miguel Arcángel; además hay uno a la Purísima Concepción de María y otro más a la Virgen de Guadalupe. A esto hay que añadir que, si bien sólo llegó a imprimirse una mínima parte de sus sermones, como ha observado Laurette Godinas, "no es descabellado pensar que Eguiara estaría preparando una edición conjunta de su obra homilética" (2015: 217). Es evidente que tuvo buen cuidado de organizarlos en varios tomos, en muchos casos también de hacerlos copiar a un amanuense que tenía mejor letra que él, de ponerles índices y también de señalar en éstos si algún sermón había sido ya publicado, o si ya consideraba algún otro listo para la imprenta o, por el contrario, como hemos visto, si no daba su autorización para que se imprimiera, "aunque la edad avanzada y la enfermedad que lo acompañó sus últimos años de vida 
ticia- entre los dedicados a san José. Para explicarnos eso, hay que tomar en cuenta que en esos años, para que un determinado sermón llegara a las prensas novohispanas, solían darse una serie de circunstancias litúrgicas, políticas y económicas de diversa índole. ${ }^{13}$ Además son de sobra conocidas las dificultades materiales, económicas y políticas para la publicación de libros de cualquier tipo en la Nueva España en tiempos de Eguiara. ${ }^{14}$

Por otra parte, habría que estudiar las fichas de la Bibliotheca Mexicana relativas a los autores de nuestras tierras que escribieron sobre el santo, lo mismo que el catálogo de publicaciones de la Imprenta de la Bibliotheca Mexicana, al igual que la lista de libros de la biblioteca personal de Eguiara, para buscar ahí todas las obras que de alguna manera tratan sobre el esposo de María.

le impidieron llevar a bien esta misión, del mismo modo que no pudo culminar con su proyecto de la Bibliotheca Mexicana" (Godinas 2015: 227).

13 La mayoría de los sermones que llegaban a las prensas probablemente lo hacían porque así lo merecía la ocasión especial, pública, en que fueron predicados; por ejemplo, el dedicado a san Esteban protomártir, que Eguiara tuvo que predicar durante una hora en su oposición a la canonjía lectoral de la Santa Iglesia Metropolitana de México, cuyo tema le fue asignado para semejante prueba (El primero de los mártires en Cristo por su magisterio [...] panegírico de san Esteban protomártir... México, 1729). Y lo mismo podría decirse de otro sermón de Eguiara publicado, también en México y también en 1729, dedicado a la canonización de san Juan de la Cruz, que fue predicado el último día del solemne novenario organizado con ese motivo por el Convento de san José de las carmelitas descalzas, con asistencia de la Universidad. Sin duda, hay todavía mucho trabajo por hacer en relación con el análisis de los aspectos editoriales y materiales de la impresión de sermones en la Nueva España del siglo XVIII; uno de los aspectos de ese análisis es la elaboración de bases de datos de los paratextos y datos de impresión de todas las obras de oratoria sagrada que se publicaron aquí a lo largo de dicho siglo. Afortunadamente contamos ya con dicha base para el siglo XVII, elaborada por Cecilia Cortés Ortiz, primero en el Instituto de Investigaciones Filológicas y después en el Instituto de Investigaciones Bibliográficas, de la UNAM, como parte del Programa de becas posdoctorales de la DGAPA y del Proyecto PAPIIT IG400418.

14 La existencia de estas dificultades queda de manifiesto en el mismo hecho de que el teólogo novohispano decidiera incurrir en el enorme gasto de comprar una imprenta española y traerla a México para imprimir con ella, ante todo, su magna Bibliotheca Mexicana... Además, a pesar de los enormes trabajos que ello supuso, en vida de Eguiara sólo llegó a imprimirse el primer volumen de esta obra, en 1755, lo mismo que sucedió con su sus Selectae Dissertationes..., cuyo primer tomo no se imprimió en la imprenta de Eguiara, que aún no existía, sino en la de la Viuda de Bernardo de Hogal, en 1746. 


\section{El tratado de Eguiara sobre san José}

Entre los escritos teológicos que nos permiten acercarnos a lo que Eguiara pensaba sobre el padre putativo de Cristo, contamos con un tratado completo: Tractatus de SS. Deigenitricis Sponso losepho, que consta de 692 párrafos y forma parte del tomo I —el único que llegó a imprimirse- de las Selectae Dissertationes Mexicanae ad Scholasticam expectantes Theologiam (Eguiara y Eguren 1746: párrs. 552-1244). Para el conocimiento de estas Dissertationes... - concebidas como texto para los alumnos de la Universidad de México-, además del volumen impreso y de los otros dos que quedaron manuscritos, resultan de gran utilidad, por un lado, la cuidadosa descripción hecha por Ernesto de la Torre de la manera como están concebidas y organizadas en su totalidad; por otro, el detallado capítulo del padre Roberto Balmori Cinta al que me referí más arriba, "La josefología de Juan José de Eguiara y Eguren" (1993: 29-52), pues va glosando con claridad y detenimiento cada uno de los párrafos que contienen las Dissertationes...

Gracias a estos trabajos sabemos que Eguiara distribuyó todo el material para esta obra en tres volúmenes; el primero de ellos contiene tres tratados: el primero habla sobre "Dios y el Uno" y los atributos divinos; el segundo, sobre "El augustísimo misterio de la Trinidad"; el tercero está dedicado íntegramente a san José, y es el que nos interesa ahora: Santísimo Deigenitricis Sponso Josepho. Este primer volumen de los tres que constituyen las Dissertationes fue, como hemos dicho, el único que llegó a imprimirse. Hay que observar que Eguiara colocó su tratado sobre san José muy al principio de su extenso curso universitario: en un tercer lugar, sólo después de los tratados sobre Dios y la Trinidad. Este solo dato debe darnos idea de la importancia que otorgaba a la josefología en sus disertaciones teológicas (Torre Villar 1992: 332-333). ${ }^{15}$ Pero vayamos al contenido del tratado.

15 El tomo segundo contiene: Tractatus IV, De Libertate creata; V, De ente supernaturali; VI, De Gratia Auxiliante; VII, De Justificatione. El tomo tercero: Tractatus VIII, De Voluntate divina; IX, De Divinis Decretis; X, De Systemate dominicae Incarnationis; XI, De Praedestinatione \& Reprobatione; XII, Theojuridicos offert titulus sex: de Dona- 
Como ya observó el padre Balmori Cinta, la doctrina sobre san José expuesta aquí por Eguiara es "en varios puntos deudora de la teología de su tiempo", y añade que "aporta sin embargo nuevos temas y matices que enriquecen notablemente la ciencia josefina" (1993: 30). Lamentablemente no señala cuáles son esos nuevos temas y matices; por tanto, cabe preguntarse si no se referirá más bien a la impecable estructuración y organización — de tipo escolástico— del tratado, ya que la mayoría de los temas que toca en él Eguiara — salvo uno, como veremos un poco más adelante- habían sido tratados por teólogos y padres desde el siglo primero de nuestra era, tratamiento que llegó a su plena madurez con san Agustín y culminó con los grandes teólogos josefinos del siglo XIV y XV a que hemos hecho referencia.

Nuestro teólogo comienza, al estilo de los tratadistas anteriores, con el tema del matrimonio de María y José, anunciado ya en el título de su tratado y que, a lo largo de la tradición, fue uno de los pilares en que se fundó la dignidad del esposo de María. El otro pilar fue la paternidad del santo, a la que Eguiara dedica varias páginas en su esfuerzo por probarla de varias formas, incluyendo un fino análisis semántico de la palabra padre y llegando a afirmar, con Gerson, que "José fue padre de Jesús por generación, no suya sino de María su esposa, con la cooperación del Espíritu Santo" (Balmori 1993: 35, párrs. 590-591). Por otra parte, Eguiara afirma también, esta vez con san Pablo — como lo había hecho también Gerson-, que "la mujer no tiene potestad sobre su cuerpo, sino el marido" (I Cor. 7.4); por tanto, si la carne de la Virgen pertenece a José y ella pertenece al orden hipostático (porque, debido a su maternidad, tiene una conexión sustancial con Dios), se sigue que también san José pertenece al orden hipostático.

Todo lo anterior refleja la clara filiación de Eguiara en relación con la rama decididamente josefina de la corriente teológica que lo precede, y lo mismo puede decirse de su tratamiento del tema de la santificación de José en el seno materno, idea que también había sido planteada por teólogos y tratadistas. Sin embargo, en este punto el autor novohispano da muestras de querer ir más lejos. Llevando la idea hasta sus últimas consecuencias,

tionibus, de Compensationibus, de Actione Pauliana, de Crimine laese Majestatis, de Confiscatione, de Vectigalibus. 
procede a sugerir lo que iba en contra de la opinión de los padres y de lo que había enseñado siempre la Iglesia: que José gozó de la prerrogativa de tener una concepción inmaculada. ${ }^{16}$ En efecto, ninguno de los grandes prelados ni teólogos se había atrevido a decir que san José, a semejanza de la Virgen María, estuvo libre del pecado original desde el momento mismo de su concepción (una de las razones que habían pesado para este impedimento consistía en el hecho de que el santo no fue padre físico de Jesucristo, sino únicamente padre putativo).

A pesar de ello, Eguiara no quiere perder la esperanza y aprovecha aquí para hacer un sutil llamado a los teólogos devotos del esposo de la Virgen. Dice lo siguiente: “Un sabio maestro de Salamanca dijo que si encontraba cinco o seis teólogos de renombre que enseñaran que san José fue preservado del pecado original, él se uniría a ellos y daría razones fuertes..." (Balmori 1993: 36, párr. 619). Al final, nuestro autor tiene que contentarse con decir únicamente lo que podía afirmarse en calidad de "opinión piadosa y probable": que José fue santificado en el segundo momento de su concepción (Balmori 1993: 37, párr. 632).

Eguiara plantea una idea que podría ser, esa sí, de su muy personal cosecha cuando habla de los privilegios de José. En este punto sostiene una opinión que también, según nos dice él mismo, puede ser considerada como "afirmación piadosa y probable", y que no he podido localizar ni en Gerson ni en los más importantes tratadistas que precedieron a nuestro teólogo. Esa idea consiste en que José gozó del uso de la razón desde que se encontraba en el vientre de su madre. En apoyo de esto, Eguiara recurre a la autoridad de Eclesiástico 49:15, aplicando al esposo de María un versículo que se refiere a José de Egipto, y distorsionando ligeramente su sentido al sacarlo de contexto y citarlo incompleto, de la siguiente manera: "Nadie nació en la tierra como José, que nació hombre".${ }^{17}$ Este giro le

16 Hay que recordar que, en tiempos de Eguiara, incluso la creencia en la Inmaculada Concepción de María no era todavía más que eso: una piadosa creencia. Si bien había sido admitida prácticamente como dogma en todo el mundo hispánico desde siglos atrás, no fue decretada como dogma de fe por el jefe de la Iglesia en Roma hasta 1854.

17 La manipulación e incluso la distorsión de citas bíblicas no puede atribuirse sólo a Eguiara; era, todavía en su tiempo, práctica común entre predicadores y tratadistas. La versión de la Vulgata, que es la que él cita en su tratado latino, dice: Nemo natus est in terra qualis Henoch, nam et ipse receptus est a terra: / neque ut Joseph, qui natus est 
permite continuar con la siguiente premisa: lo que caracteriza al hombre y lo distingue de los animales y de los infantes es la razón; finalmente llega a la conclusión que le interesa mostrar: si la Biblia dice que José nació hombre debemos asumir que nació ya con pleno uso de la razón.

\section{Obras sobre san José publicadas por la Imprenta de la Bibliotheca Mexicana}

Una primera revisión del catálogo publicado por Ernesto de la Torre Villar en el mismo volumen $\mathrm{V}$ de la Bibliotheca Mexicana (Monumenta eguiarense) nos da un total de 12 obras impresas de distintos autores sobre san José durante los nueve años que Eguiara tuvo la imprenta (entre ellas hay algunas reimpresiones). ${ }^{18}$ Ya nos hemos referido a las dificultades que entrañaba imprimir una obra en la Nueva España aún para conocidos intelectuales como nuestro autor, hecho que hace más significativo el que Ilegara a publicarse más de un libro sobre san José cada año durante el lapso en que estuvo al frente de su imprenta. Cuatro de los impresos están dedicados a los "gozos y dolores de san José", devoción que imitaba la de los gozos y dolores de la Virgen, y que se extendió mucho durante los siglos XVII y XVIII.

Los "siete gozos y siete dolores de san José" constituyeron una devoción de tinte popular que solía tomarse como guía para realizar sencillas meditaciones devotas en torno a la vida de la Sagrada Familia. Por ejemplo, se hacía una meditación en torno al primer dolor de José: las dudas

homo princeps fratrum, firmamentum gentis, rector fratrum, stabilimentum populi: / et ossa ipsius visitata sunt, et post mortem prophetaverunt (Eci. 49:16-18). La versión más literal que encuentro de este pasaje al castellano es la de la Biblia de Jerusalén (Eclo. 49:14-15): "Nadie fue creado en la tierra igual a Henoc, / pues él fue arrebatado de la tierra. / Ni como José nació hombre alguno, / el guía de sus hermanos, apoyo de su pueblo; / sus huesos fueron visitados" (Biblia de Jerusalem 1975).

18 La Imprenta de la Bibliotheca Mexicana se funda en 1753 y Eguiara muere en 1762. El bibliógrafo novohispano la fundó, como hemos dicho, para poder imprimir su magna obra del mismo nombre, que quedó inconclusa y de la que sólo alcanzó a imprimir un volumen (Eguiara 1755). Los otros tres que alcanzó a escribir tuvieron que esperar inéditos hasta que Ernesto de la Torre Villar se hizo cargo, entre1986 y 1989, de la edición de los dos primeros; y nuevamente hasta 2010, cuando Germán Viveros editó el tercero (véase Godinas 2012). 
y vacilaciones que lo asaltaron cuando cayó en la cuenta de que María estaba encinta, y que lo llevaron a la idea de abandonarla; acto seguido se hacía otra meditación en torno al primer gozo del santo: la revelación angélica. Y así sucesivamente se procedía con cada uno de los dolores y de los gozos del padre de Jesús. Hay que decir que algunas de estas devociones no estuvieron exentas de sospecha, e incluso fueron condenadas por la Iglesia, especialmente cuando incluían versiones alteradas o contrahechas — contrafacta - del rosario o de algunas oraciones como el Ave María. Al respecto Francisco de la Maza observó que

durante el siglo XVII se escribieron varios libros y devociones sobre san José, incluso algunas obras heréticas, como la del Rosario del Gloriosísimo Patriarca Señor San Joseph, impresa en 1679 por la viuda de Bernardo Calderón, y la Hora y Rosario perpetuo a los gozos y dolores del Señor San Joseph, 1680, en Puebla por la viuda de Juan Borja, las cuales, a pesar de que tenían indulgencias archiepiscopales, fueron condenadas por la Inquisición. Esta última comenzaba: "Dios te salve, José, por excelencia justo entre todos los varones" (cit. en Morán 1981: 962). ${ }^{19}$

Otro ejemplo de la difusión de este tipo de publicaciones en el mundo hispánico de los siglos XVII y XVIII es el del "Oficio del glorioso san Joseph", que está incluido en un devocionario castellano que circuló ampliamente en la Nueva España: el Ramillete de divinas flores escogidas en las obras de muchos santos y mejores autores... ${ }^{20}$ Contiene un "Ave María a San Joseph", un "Pater noster a San Joseph" y una letanía al santo, además de otras oraciones breves, himnos y antífonas igualmente dedicadas al esposo

19 También el jesuita Antonio Núñez — confesor de sor Juana- parece haber sido devoto del santo, como se trasluce en una cartilla suya que dio a conocer Dolores Bravo en su libro El discurso de la espiritualidad dirigida (2001). A propósito de esta cartilla, Antonio Alatorre observó que dos capítulos fueron "enérgicamente castigados", seguramente por autocensura del mismo Núñez, pero pudo identificar una parte tachada que rezaba: "Glossa mental del Padre nuestro a san Joseph" (2003: 12).

20 Debo la noticia de este devocionario a Olivia Moreno Gamboa. En un trabajo suyo, ricamente documentado, la autora hace un análisis del funcionamiento de la censura inquisitorial en la Nueva España y de su relación con la edición, la circulación y el comercio de libros entre la Metrópoli y las colonias. Ahí menciona, por cierto, al padre Antonio Núñez como calificador del Ramillete... en 1690, cuando la Inquisición, debido a las quejas de los mercaderes y libreros afectados, permite la corrección del devocionario para que pueda seguir vendiéndose (Moreno 2016: 172-173 y n. 22). 
de la Virgen. Escrito por un hombre lego (el mercader de libros Bernardo de Sierra), el devocionario se editó por primera vez en Madrid en 1661 y tuvo una enorme fortuna editorial durante los cien años siguientes, aun cuando en 1671 el inquisidor general ordenó recogerlo y prohibirlo, en gran parte debido al "Oficio de san José" que contenía (Sierra 1670: 269-285). ${ }^{21}$ A pesar de lo anterior, o precisamente por ello, no deja de ser significativa la relativa abundancia de "gozos de san José" — tres de un total de doce obras - publicados por la Imprenta de la Bibliotheca Mexicana. Los siguientes son los libros sobre el santo que salieron de dicha imprenta en vida de Eguiara:

1. Gozos y dolores del S. Patriarcha S. S. Joseph, publicados a devoción de "un devoto" y reimpresos en México, México: Imprenta de la Bibliotheca Mexicana, 1755.

2. Exorcismo y evangelios del señor san José, a devoción del brigadier Antonio Dionisio de Arellano, México: Imprenta de la Bibliotheca Mexicana, 1757.

3. Modo de rezar los dolores y gozos del gloriosísimo patriarca s. Joseph. A devoción de su congregación [...] en el Colegio de san Gregorio de México, quinta impresión. México: Imprenta de la Bibliotheca Mexicana, 1757.

4. Septenario al glorioso Patriarcha S. Joseph de los siete privilegios de su Patrocinio, que refiere la venerable madre María Jesús de Agreda en su Mística Ciudad de Dios [...] para que se lean [...] al tiempo de las siete misas que se cantan al tiempo de los nueve días antecedentes al de santa Teresa de Jesús, a devoción de la Congregación de san Felipe Neri. Reimpreso [...] México: Imprenta de la Bibliotheca Mexicana, 1757.

5. TORRES, fray Ignacio de, Salud y gusto para todo el año. $O$ año josefino [...] México, Imprenta de la Bibliotheca Mexicana, 1758.

21 En la edición que pude consultar —la de Bruselas de 1670, en los talleres de Francisco Foppens-, el "Oficio del glorioso san Joseph" va de la página 269 a la 285. Las ediciones posteriores a 1671 están más o menos expurgadas; en todas ellas, según se entiende del artículo de Moreno Gamboa, se eliminó el oficio de san José. 
6. Escobar y Mendoza, Antonio de, Nueva Jerusalem. María Señora. Poema heroico [...], a devoción de un devoto de san José quien en esta nueva reimpresión [...] lo dedica al mismo Santissimo Patriarcha. México: Imprenta de la Bibliotheca Mexicana, 1758.

7. Gozos y dolores del santísimo Patriarca SS José, a devoción de una religiosa del convento de la Encarnación. México: Imprenta de la Bibliotheca Mexicana, 1758.

8. Gozos y dolores del santísimo Patriarca SS José, a devoción de un devoto. México: Imprenta de la Bibliotheca Mexicana, 1758.

9. Segura y Alzaga, Joaquín Antonio, El benefactor de todo el género humano, y de su mismo benefactor y cabeza nuestra, Cristo, vida nuestra, el S.S. Joseph. Sermón panegírico. México: Imprenta de la Bibliotheca Mexicana, 1758.

10. Desagravios. México: Imprenta de la Bibliotheca Mexicana, 1758.

11. Escobar y Mendoza, Antonio de, Nueva Jerusalem [...]; México: Imprenta de la Bibliotheca Mexicana, 1759 [reimpresión del núm. 6].

12. TORRes, Salud y gusto para todo el año. México: Imprenta de la Bibliotheca Mexicana, 1760 [reimpresión del núm. 5].

Además de diversos volúmenes de Suárez, y aparte de los abundantes sermonarios que aparecen en la lista de libros de la biblioteca de Eguiara — que seguramente habrán incluido varias piezas sobre el santo—, las obras dedicadas íntegramente a san José en su biblioteca personal no son tantas como podría suponerse. En efecto, encontramos sólo tres libros dedicados exclusivamente al esposo de la Virgen en esta lista: "Excelencias del Sr. San Joseph, de Torres"; "Magnalia S. Joseph, de Bravanti"; y una anónima "Práctica de la devoción de señor san Joseph". ${ }^{22}$ Hay que tomar

22 La primera de estas obras debe ser la del jesuita Pedro Torres que se encuentra en el Fondo Reservado de la Biblioteca Nacional de México: Excelencias de S. Joseph, varón divino, patriarca grande, esposo purísimo de la madre de Dios [...] Sevilla, Herederos de Tomás López de Haro, 1710 (tiene marcas de fuego de la Real y Pontificia Universidad de México y del convento de san Diego, y ex libris del Convento de san Diego y de la Casa Profesa, de México); de la segunda no he podido averiguar nada, y la tercera puede ser una de las numerosas obras de título semejante que se publicaron durante los siglos XVII y XVIII, como la que se encuentra en el Fondo Reservado de la Biblioteca Nacional de México bajo las siglas RSM 1815 M4DEV: Devoción a señor San 
en cuenta, sin embargo, como observa De la Torre Villar, que esta lista "no hace mención de sus colecciones documentales, que él cita numerosas veces en la Bibliotheca Mexicana" (1989a: 193). Por otra parte, también hay que considerar que el sabio novohispano podía consultar fácilmente las ricas bibliotecas a que tenía acceso "como canónigo de la Catedral de México, antiguo colegial de san Ildefonso, creador de la Academia Filosófica de san Felipe Neri y amigo de jesuitas, eclesiásticos de renombre y ricos bibliófilos" (193).

\section{Eguiara, Vicente López y san José}

Otra prueba externa que apoya la tesis de la especial devoción de Eguiara por nuestro santo puede encontrarse en el breve prólogo en prosa que el gran amigo, colaborador y "animador" — como lo llama don Ernesto de la Torre- suyo, el jesuita Vicente López, escribe para sus Dissertationes. En él elogia expresivamente la labor de su amigo como teólogo, encareciendo de manera muy especial los capítulos que dedica a san José:

debiéndose agradecer a nuestro ingeniosísimo catedrático de prima el haber así allanado para nosotros las más difíciles cuestiones de toda la teología, y sacándolas con sus desvelos, como quien dice, al sol, hay algo que no podríamos dejar sin alto pregón y alabanza sin que la piedad misma y la religión nos lo reprendieran, y es el hecho de no sólo haber sacado cuanto en sí había de erudición escolástica y vigor, sino el haberlo casi agotado para exaltar a José, padre de Cristo y esposo castísimo de la Señora de la creación, poniendo aquí, escritor de maravillosa diligencia, todo el nervio, abundancia y riquezas de su ánimo. Tales son, pues, las lucubraciones de nuestro doctor, no solo libres de sombras y lunares, sino capaces de acrecentar extremadamente el esplendor de la teología (Torre Villar 1989c: 546).

A continuación, el hermoso poema laudatorio del mismo Vicente López se dedica también en su totalidad a elogiar el tratamiento que hace Eguiara de san José. Vale la pena citarlo completo en la excelente traducción de Salvador Díaz Cíntora:

José, por los Padres jesuitas Francisco García (1641-1685) y Juan Nadasio (1613-1679), publicada en México en la Imprenta de Ontiveros en 1815. 
Vayas con buen agüero, de las Gracias parto feliz, oh libro, y toda Europa te lea. Atenas léate con ansia, ni de César la lanza o de Quirino te defiendan; modestas las olivas te agradan que la mano de Minerva sembró fecunda, de quien fuiste siempre campeón esforzado; con violetas las sienes ciñes de José, más blancas que la nieve, y te alegras de adornarlo con las joyas que antaño le escondieran el mal error y la maligna noche; su faz con tu elegante y rico ingenio haces lucir, le das de sus diamantes el esplendor real: Ilámenlo padre con gran aplauso los gemelos orbes. A aquel niño dos veces engendrado, casto padre, José, con miel nutría y con crema del Líbano; a las tierras de Faro huyendo, arrebató a la espada, a la muerte, al tirano, la cabeza querida; mira Eguiara con alegre rostro y ánimo grato del Tonante la casa esplendorosa, mete el libro en el fondo del seno, mas lo adorna luego con bermellón y oro luciente, y gemas verdes pónele por broches; mas, ¿quién podrá pagar el digno precio de libro tal? Si acaso amor no engaña a los poetas, te leerá el Olimpo; lauro debido en superior teatro

(Torre Villar 1989c: 546-547; el énfasis es mío).

La referencia al niño "dos veces engendrado" habría sido, casi con seguridad, transparente para el lector culto de esas Dissertationes en el siglo XVIII, pero quizá hoy no lo sea tanto: se trata del niño Jesús que, como había dicho san Agustín (In Joannis Evangelium...) y repetían los teólogos del momento, fue engendrado, por una parte, en la carne, y por la otra en el espíritu (sin padre según la carne y sin madre según el espíritu). Lo cual está además en clara concordancia, por una parte, con lo que habían 
dicho los teólogos a partir del obispo de Hipona, y, por otra, con la josefología de Eguiara tal como aparece en su Tratado sobre san José. ${ }^{23}$

También he subrayado las palabras con que Vicente López le augura éxito al tratado de Eguiara: "[...] toda Europa / te lea. Atenas léate con ansia", y la expresión que utiliza para referirse a quienes dirán las alabanzas del padre nutricio de Jesucristo: los gemelos orbes ("Llámenlo padre, con gran aplauso, los gemelos orbes"). En ambos casos se trata de palabras que, no por tópicas en las letras novohispanas y americanas en general, dejan de aludir claramente al deseo de trascender las fronteras geográficas y culturales de América, así como a la necesidad por parte de teólogos y hombres de letras americanos de hacerse presentes en la cultura europea.

Vicente López compartió con el autor de la Bibliotheca Mexicana no sólo el deseo de reivindicación de la cultura americana $-\mathrm{y}$ específicamente la mexicana - frente a Europa, sino también una evidente devoción por san José. Tenemos noticia, gracias a la "carta edificante" ${ }^{24}$ que otro jesuita —el suizo Juan Antonio Baltasar- escribió a sus superiores a la muerte del mismo Vicente López, de que éste había preparado una antología con todos los textos que pudo reunir sobre el padre putativo de Jesucristo escritos por teólogos y padres de la Iglesia. Valdés García y Vargas consideran perdido este trabajo, junto con algunos otros. ${ }^{25}$ Escribe Baltasar:

23 En el siglo xvı el poeta Fernán González de Eslava (quien nació en 1534, y llegó a la Nueva España a los veinticinco años) escribe una canción dedicada al episodio en que el niño Jesús se les pierde a sus padres y san José va por las calles preguntando a la gente si lo ha visto. Las señas que da del niño son precisamente éstas: "Un mysterio soberano / da por señales su padre: / que, en quanto Dios, es sin madre, / y sin padre en quanto humano" (1989: 196).

24 Las cartas edificantes —además de otras de carácter más burocrático- eran producto de una práctica generalizada entre los jesuitas. Su difusión, casi siempre manuscrita, entre las comunidades obedecía a diversos objetivos: la comunicación e información dentro de la orden (difundir noticias, reportar sucesos, mantener comunicadas entre sí a las diferentes comunidades); la formación y el fortalecimiento de la identidad apostólica; el fomento del deseo de emulación de vidas y acciones paradigmáticas de otros jesuitas; la propaganda hacia dentro y fuera de la orden (Palomo 2005: 57-81).

25 "Sobre las obras perdidas [de Vicente López] tenemos como testimonio la carta edificante que escribió el 21 de febrero de 1757 el padre Juan Antonio Baltasar; en ella 
Sabemos también que, pocos meses ha, se remitieron para España unos papeles para que logren la pública luz, efectos de su [de Vicente López] tierna devoción al patriarca señor San José, en que, con prolijo estudio y esmero, por muchos años fue trabajando y entresacando, de todos los Santos Padres y demás autores que pudo tener a la mano, cuanto habían escrito en alabanza del santísimo patriarca, para que, así juntas todas sus excelencias, moviesen más fácilmente los ánimos de los lectores al culto y devoción del gloriosísimo santo, pues aunque no nos consta que el padre Vicente de lo suyo añadiese alguna cosa propia, que no será muy difícil, con todo eso es digno del mayor elogio el celo y afán de haber recogido cuanto podía contribuir al engrandecimiento del señor San José (Vargas 1987: XXVI-XXXV). ${ }^{26}$

El jesuita, nacido en Andalucía y trasladado por voluntad propia a América antes de cumplir los 16 años, fue, junto con su amigo Eguiara, un intelectual defensor de la cultura novohispana, como puede apreciarse en su obra más conocida, el Diálogo de abril, y en los demás paratextos que escribió para la Bibliotheca Mexicana. Fue aquí donde terminó sus estudios y se ordenó sacerdote; aquí donde enseñó artes y letras en diferentes colegios jesuitas de Puebla y México, y aquí donde aprendió el náhuatl para confesar y predicar a los indios del Colegio de san Gregorio de México, aunque esta última actividad parece habérsele dificultado por la precariedad crónica de su salud. Además, el temperamento no debe haber ayudado a predicar ante grandes auditorios a este jesuita más bien callado que mantuvo siempre un bajo perfil, que a todas luces prefirió la soledad del estudio al ruido mundano, y que prefirió escribir al margen de otros — de la obra de su correligionario y amigo Eguiara - y recopilar sentencias y escritos de otros —el caso de las colecciones sobre san José, la Virgen María y los santos - antes que dejar salir con fuerza su propia voz. ${ }^{27}$ El hecho es que no resulta difícil imaginar la afinidad que sentiría

se da noticia de la obra sobre san José" (Valdés 2005: 480). Los otros documentos perdidos que menciona la carta son dos tomos en que recogió sentencias en alabanza de la Virgen María, y "varios otros tomitos manuscritos y en ellos recopilados los elogios de muchos otros santos" (Vargas 1987: xxxv).

26 La carta, fechada el 21 de febrero de 1757, fue transcrita por primera vez por Silvia Vargas Alquicira e incluida en su edición del Dialogo de abril, de Vicente López.

27 El mismo padre Baltasar hace alusión a estos rasgos de carácter en su "Carta edificante del Padre Vicente López" y cuenta una anécdota que los ilustra (Vargas 1987: XXIX-XXXIV). Por otra parte, el informe de la Compañía de Jesús (Informatio de 
por el silencioso padre nutricio de Cristo este jesuita que se entregó calladamente al cuidado y evangelización de los más débiles —los indios-, así como a un trabajo intelectual humilde y devoto.

\section{Consideraciones finales}

Para comprender en toda su complejidad la devoción que tuvo el autor de la Bibliotheca Mexicana hacia san José, tendremos que estudiar con cuidado, en primer lugar, todos los sermones, pláticas y apuntes de sermones que este prolífico autor novohispano dedicó al esposo de la Virgen, además de una buena muestra de otras producciones homiléticas sobre temas diversos. Esa labor necesariamente deberá ir acompañada del rescate y edición de varios volúmenes del autor que aún permanecen manuscritos, pues, como hemos señalado, sólo una mínima parte de sus sermones se imprimieron. Por otra parte, tendremos que analizar a fondo su tratado sobre san José —este sí, afortunadamente, impreso, aunque necesitado de una edición moderna acompañada de su traducción al español— en el contexto de la teología de su tiempo, al igual que su labor magisterial y editorial.

En todo caso, debemos tener presente que la devoción personal del erudito Eguiara, por genuina y profunda que haya sido, se debió en parte a un sentimiento, por así decirlo, disciplinado, que se adaptó a las corrientes ideológicas, religiosas y culturales de su época. En ese sentido, Eguiara participó plenamente de esas corrientes que elevaban a san José al rango de patrono y protector de la Iglesia mexicana, jefe y proveedor de la Sagrada Familia, baluarte de la virtud doméstica y del trabajo callado. Y por otra parte, la inclinación que sintió esta gran figura de nuestras letras por el padre de Jesucristo quizá también podría explicarse por el temperamento

\footnotetext{
p[atre] Vincentio Lopez) enviado a Roma el 1 de abril de 1721 señala en su séptimo punto: "Tuvo sermones por algún tiempo y con mayor utilidad que gracia; pues carece de talento para ellos [...] Oye confesiones con fruto y a este trabajo ha sido aplicado, según todos"; en su octavo punto: "Nunca gobernó"; y en su décimo punto: "Es devoto y dado a la oración, y tiene celo de las almas, según todos [...] Ni pretendió el cargo de regir ni aspiró al sacerdocio o a la profesión, sino indiferente a cualquier grado en la Compañía es visto según todos" (transcrito y traducido por Vargas 1987: XLI-XLIII).
} 
personal de este sabio novohispano, que llevó una vida rigurosa y por entero entregada al servicio, no de una familia como hoy la conocemos sino de una comunidad que sintió como propia, de una república letrada, y de unos valores y unas convicciones trascendentes. Inclinación que puede explicarse, en suma, por lo que parece ser la tendencia de nuestro teólogo a privilegiar la disciplina de la razón sobre otras formas de conocimiento o, mejor aún, por su tendencia a someter a ella el imperio, desordenado y oscuro, del deseo. Como hemos podido ver, cuando nos muestra la imagen del santo en el vientre de su madre, el severo sabio novohispano nos permite asomarnos por un momento a su idea de los atributos que debe tener el varón justo por antonomasia que es José. Un José que, si en pura teología no puede llamarse inmaculado, puede verse, sin embargo - a ojos de nuestro teólogo-, ya perfectamente armado de la conciencia y del uso de la razón, como otra Minerva que brota del muslo de Zeus plenamente armada para la guerra.

\section{Bibliografía}

Alatorre, Antonio. "Sobre el P. Núñez, confesor de sor Juana (a propósito de dos libros recientes)", en Literatura Mexicana, XIV-1 (2003): 7-22.

Balmori Cinta, Roberto M. J. "La josefología de Juan José de Eguiara y Eguren”, en Ernesto de la Torre Villar (coord.). Juan José de Eguiara y Eguren y la cultura mexicana. México: Universidad Nacional Autónoma de México, 1993. 29-52.

Biblia de Jerusalen. Edición española, dirigida por José Ángel Ubieta. Nueva edición totalmente revisada y aumentada. Bilbao: Desclee de Brouwer, 1976.

Bravo, Dolores. El discurso de la espiritualidad dirigida. México: Universidad Nacional Autónoma de México, 2001.

CASTAÑO, ANA. “Un sermón de Juan José de Eguiara y Eguren sobre san José: La congregación de todos los ángeles y hombres santos excedida por san José (Manuscrito 760 de la Biblioteca Nacional de México)", en (an)ecdótica, vol. III, núm. 2 (julio-diciembre 2019): 95-103. Artículo en línea disponible en: <https:// revistas-filologicas.unam.mx/anEcdotica/index.php/anec/article/view/ $68 / 46>$.

Concilio de Trento. El sacrosanto y ecuménico Concilio de Trento. Traducido al idioma castellano por Ignacio López de Ayala. Barcelona: Imprenta de don Ramón Martín Indar, 1847.

Eguiara y Eguren, Juan José De. Tractatus de SS. Deigenitricis Sponso losepho, en Selectae Dissertationes Mexicanae ad Scholasticam expectantes Theologiam [párrafos 552 al 1244]. México: Viuda de Bernardo de Hogal, 1746. Versión digital en la BNM. 
Eguiara y Eguren, JuAn José De. Bibliotheca Mexicana sive Eruditorum Historia virorum, qui in America Boreali nati [...], tomus primus, litteras A, B y C, Mexici, ex nova Typographia in aedibus authoris editioni eiusdem Bibliothecae destinata. México: Imprenta de la Bibliotheca Mexicana, 1755.

Eguiara y Eguren, Juan José De. El Ángel de la guarda de Cristo Señor Nuestro: el esclarecido Patriarcha el Señor San Joseph. Apuntes de sermón que el día 19 de marzo de 1722, en la iglesia de la Congregación del Oratorio de Nuestro Padre San Phelipe Neri de Mexico, predicó el Doctor Don Juan José de Eguiara y Eguren, fols. $85 r^{\circ}$ al $88 v^{\circ}$ [Según el índice, hay en ese volumen otras dos pláticas a san José a continuación de ésta (núms.12 y 13). Al final de dicho índice dice: "Éstos no permito a imprenta"].

Eguiara y Eguren, Juan José DE. El día de la invención de la Santa Cruz en su víspera. Plática que a 3 de mayo de 1727, víspera del Patrocinio del esclarecido patriarca S. S. Joseph, que en la Iglesia de N S S Phelipe Neri de México predicó el D. Juan Joseph de Eguiara y Eguren. Folios: 50r $-56 r^{\circ}$.

Filas Francis L. S. J. The man nearest to Christ. Nature and Historic Development of the Devotion to Saint Joseph. Milwauwkee: The Bruce Publishing Co., 1945.

Gerson, Jean. "In Festo Nativitatis B. Mariae Virginis" (Incipit: Mt. 1:16), en Oeuvres complètes. Vol. V. Introd. texte et notes par Mgr Glorieux. Paris: Desclée \& Cie, 1961. 344-364.

Godinas, Laurette. "Eguiara y Eguren, Juan José, Bibliotheca Mexicana, t. III. Edición de Germán Viveros. México: Universidad Nacional Autónoma de México [...]" [reseña], en Nova Tellus 30, núm. 2 (2012): 335-342.

GODINAS, LAURETTE. "El laboratorio del sermón. La colección de manuscritos homiléticos de Juan José de Eguiara y Eguren en la Biblioteca Nacional de México", en Hilda Julieta Valdés García y Alejandra Valdés García (eds.). Reminiscencias novohispanas. México: Universidad Nacional Autónoma de México / Instituto de Investigaciones Filológicas, 2015. 213-227.

GONZÁlez de Eslava, Fernán. Villancicos, romances, ensaladas y otras canciones devotas. Edición crítica, introducción, notas y apéndices de Margit Frenk. México: El Colegio de México, 1989. 196.

LóPEZ, Vicente. Diálogo de abril. Acerca de la Bibliotheca del señor doctor Juan José de Eguiara y del ingenio de los mexicanos. Introducción, traducción y notas de Silvia Vargas Alquicira. México: Universidad Nacional Autónoma de México / Instituto de Investigaciones Filológicas, 1987.

Morán, JuAn ANTONIO. m.i. "La devoción a san José en México en el siglo XVII. Introducción", en San José en el siglo XVII. Actas del Tercer Simposium Internacional. Montréal, 14-21 septiembre 1980. Valladolid: Centro Español de Investigaciones Josefinas, 1981. 952-999.

Moreno Gamboa, Olivia. “Disonancias entre la Inquisición de México y la Suprema. A propósito de la censura del Ramillete de divinas flores (1690-1711)", en Francisco Cervantes Bello y María del Pilar Martínez López-Cano (coords.). La dimensión imperial de la Iglesia novohispana. México: Instituto de Ciencias Sociales y Humanidades / Benemérita Universidad Autónoma de Puebla / Instituto de Investigaciones Históricas / Universidad Nacional Autónoma de México, 2016. 165-198. 
Palomo, Federico. "Corregir letras para unir espíritus: los jesuitas y las cartas edificantes en el Portugal del siglo Xvı", en Cuadernos de Historia Moderna. Anejos. IV (2005). 57-81.

Ragon, Pierre. "Los santos patronos de las ciudades del México central (siglos XVI y XVII)", en Historia Mexicana, 52-2 (2002): 361-389.

Sierra, Bernardo. Ramillete de divinas flores. Escogidas en las obras de muchos santos y mejores autores que las han escrito y observado en aumento del delicioso jardín de la Iglesia, atadas en este ramillete para recreo y aprovechamiento del buen cristiano, reducidas a mucha brevedad y eficacia. Bruselas: Francisco Foppens, 1670. Disponible en: <https://books.google.com. $\mathrm{mx} /$ books? id=gGY8AAAAcAAJ\&pg=RA2-PA283\&source=gbs_selected_ pages $\& \mathrm{hl}=\mathrm{es}-419 \# \mathrm{v}=$ onepage $\& \mathrm{q} \& \mathrm{f}=$ false $>$ [consultado el 10 de agosto de 2018].

TORRE VilLar, ERnesto de LA. "Apéndice III. La biblioteca de Eguiara", en Juan José Eguiara y Eguren. Bibliotheca Mexicana. Vol. V. Monumenta Eguiarense. Comp., pról. y notas de Ernesto de la Torre Villar. México: Universidad Nacional Autónoma de México / Coordinación de Humanidades, 1989a. 193-206.

TORRE VilLar, ERnesto de LA. "Apéndice IV. Eguiara y Eguren y la oratoria sagrada", en Juan José Eguiara y Eguren. Bibliotheca Mexicana. Vol. V. Monumenta Eguiarense. Comp., pról. y notas de Ernesto de la Torre Villar. México: Universidad Nacional Autónoma de México / Coordinación de Humanidades, 1989b. 207-239.

Torre Villar, ERnesto de LA. "Apéndice X", en Juan José Eguiara y Eguren. Bibliotheca Mexican. Vol. V. Monumenta Eguiarense. Comp., pról. y notas de Ernesto de la Torre Villar. México: Universidad Nacional Autónoma de México / Coordinación de Humanidades, 1989c. 543-622.

TORRE VilLar, ERnesto DE LA. "Juan José de Eguiara y Eguren, teólogo novohispano", en Anuario de historia de la Iglesia 1. 1992. 325-347.

Valdés García, Olga. "El humanista Vicente López (s. xVIII). Una carta inédita", en Memoria del XVIII Encuentro Nacional de Investigadores del Pensamiento Novohispano. México: Universidad Nacional Autónoma de México / Instituto de Investigaciones Filológicas / Universidad Autónoma de San Luis Potosí, 2005. 478-483.

Valdivielso, José De. Vida, excelencias y muerte del Gloriosísimo Patriarca San Joseph. Toledo: Pedro Rodríguez, 1604. Digital en la Biblioteca Complutense: $<$ http://alfama.sim.ucm.es/dioscorides/consulta_libro.asp?ref=B20521078\& idioma $=0>$.

VARGAS AlQUiCIRA, SILVIA (introducción, traducción y notas). Diálogo de abril, de Vicente López. México: Universidad Nacional Autónoma de México / Instituto de Investigaciones Filológicas, 1987.

Vergara Castro, luz Elena. Catálogo de manuscritos de Juan José de Eguiara y Eguren en la Biblioteca Nacional de México. Tesis de Licenciatura en Bibliotecología. México: Universidad Nacional Autónoma de México, 2012.

Vergara Castro, luz Elena. Identificación de los nexos informativos en los sermones manuscritos de Juan José de Eguiara y Eguren: su comportamiento 
histórico-bibliométrico. Tesis de Maestría en Bibliotecología y Estudios de la Información. México: Universidad Nacional Autónoma de México, 2016.

Villaseñor Black, Charlene. Creating the Cult of Saint Joseph. Art and Gender in the Spanish Empire. Princeton: Princeton University Press, 2006.

Vulgata. Disponible en línea: <https://www.biblegateway.com/passage/?search=E clesi\%C3\%A1stico+49\&version=VULGATE.> [consultado el 7 de mayo de 2019].

\section{Ana Castaño Navarro}

Estudió licenciatura y créditos de la maestría en Letras Hispánicas en la UNAM; cursó estudios de especialización en Madrid y Málaga. Después concluyó maestría y el doctorado en literatura española (Siglos de Oro) en la Universidad de Maryland. Investigadora del Centro de Poética desde 1993 y coordinadora del mismo de 2009 a 2013. Miembro del Sistema Nacional de Investigadores (SNI) nivel 1 de 1999 a 2009, y nivel C del PRIDE desde 2000. Previamente fue redactora del Diccionario del español de México (1982-1983; 1985-1986). Dictaminadora de numerosos artículos, libros y proyectos dentro y fuera de la UNAM. 